\title{
UM NOVO MODELO PARA OS SÍTIOS DE INTERAÇÃO DOS ANTAGONISTAS H, BASEADO NA CARACTERIZAÇÃO QUÍMICA DOS SÍTIOS PRIMÁRIO E SECUNDÁRIO POR QSAR - 3D
}

\author{
Ronaldo Lepesqueur Fabiano e Carlos Alberto Montanari* \\ Departamento de Química, Universidade Federal de Minas Gerais, CP 702, 31270-901 Belo Horizonte - MG
}

Recebido em 7/8/02; aceito em 28/10/02

\begin{abstract}
A NEW MODEL FOR THE $\mathrm{H}_{2}$ ANTAGONISTS BINDING SITE BASED ON 3D QSAR ANALYSIS. A new model for the $\mathrm{H}_{2}$ antagonists binding site is postulated based on adsorption coefficient values of sixteen antagonists, in the affinities constants of the primary and secondary binding sites, and in the chemical characterization of these sites by 3D-QSAR. All study compounds are in the extended conformation and deprotonated form. The lateral validation of the QSARs, CoMFA analysis, affinity constants and chemical similarity data suggest that the antagonists block the proton pump in the $\mathrm{H}_{2}$ receptor interacting with two tyrosines - one in the helix 5 , and other in the helix 6.
\end{abstract}

Keywords: $\mathrm{H}_{2}$ antagonists; affinity constants; 3D QSAR.

\section{INTRODUÇÃO}

$\mathrm{O}$ receptor histaminérgico $\mathrm{H}_{2}$ é constituído de sete transmembranas $^{1}(7 \mathrm{TM})$ capazes de ativar a proteína G, e pela análise comparativa da seqüência de aminoácidos das 7TM de 225 receptores acoplados à proteína $\mathrm{G}$ (GPCR) este receptor foi catalogado como pertencente à super família da rodopsina². A análise filogenética molecular deste receptor não revelou uma ramificação comum com os receptores histaminérgicos ${ }^{3} \mathrm{H}_{1}$ e $\mathrm{H}_{3}$, possivelmente devido à $\mathrm{TM}$ 5, cuja sequiência 183-187 desta TM é específica para este receptor. A hélice 5 é capaz de acomodar agonistas e antagonistas, e pode estar envolvida no processo de ativação da proteína $\mathrm{G}$ via transferência de prótons ${ }^{4}$.

Como constituintes naturais dos GPCRs, as transmembranas são proteínas reativas com respeito a esta proteína, sendo capazes de produzir respostas celulares na ausência do agonista ${ }^{5}$, como por exemplo, pela remoção de íons sódio ${ }^{6}$. Estes dados são evidências de que estes receptores podem existir em diferentes estados conformacionais (cujo comportamento é classificado como intrínseco) e são capazes de interagir com a proteína $\mathrm{G}$, mediante os vários estados ativos ${ }^{5}$ (comportamento interativo). Neste caso, o receptor é dito ativado e, portanto, a adsorção de ligantes é dependente destes estados conformacionais.

No tocante ao receptor histaminérgico $\mathrm{H}_{2}$, Nederkoorn et al. demonstraram por modelagem molecular ${ }^{7}$, que o estado ativado deste receptor pode ser caracterizado pela interação do anel heterocíclico do agonista com uma tirosina na hélice 5 e, posteriormente, com outra tirosina na hélice 6 , sem que o agonista (a histamina) se dissocie do íon aspartato na hélice ${ }^{4} 3$. Segundo este modelo, o processo de ativação do receptor $\mathrm{H}_{2}$ consiste em um transporte de prótons mediado pelo agonista (histamina) entre as tirosinas das hélices 5 e 6 e, posteriormente, entre as tirosinas das hélices 6 e 7, sem que haja a participação do agonista permitindo, assim, a ativação da proteína ${ }^{4}$ G. Não obstante, um possível bloqueio destes resíduos por um antagonista não foi, ainda, caracterizado.

$\mathrm{O}$ modelo atual do sítio de interação dos antagonistas $\mathrm{H}_{2}$ é baseado em valores teóricos da energia de interação dos ligantes com o

*e-mail: montana@dedalus.lcc.ufmg.br sítio receptor ${ }^{8}$. Todos os antagonistas estão na forma protonada e interagem com dois resíduos de aspartato existentes na terceira e quinta transmembranas do receptor $\mathrm{H}_{2}$. $\mathrm{O}$ resíduo de aspartato presente na terceira a hélice constitui o local de ação dos agonistas $\mathrm{H}_{2}$ na forma protonada ${ }^{7}$, e o segundo resíduo de aspartato na quinta alfa hélice é um sítio âncora. Um íon $\mathrm{AH}^{+}$foi usado para modelar um resíduo protonado de lisina, arginina ou histidina capaz de atuar como um doador de prótons no sítio receptor.

Este presente modelo tem apresentado várias incongruências com os dados experimentais gerados nos últimos anos. Por exemplo, segundo o modelo proposto o anel imidazólico da cimetidina (composto 11 na Tabela 1) está protonado no sítio receptor, contudo, o íon imidazólio é o mais potente ácido existente na química bioorgânica ${ }^{9} \mathrm{e}$ pode protonar qualquer resíduo de aspartato no receptor $\mathrm{H}_{2}$. Estudos cristalográficos sobre a cimetidina em meio aquoso mostraram que este composto desprotona quando cristaliza, apresentando-se na conformação estendida, e na forma neutra mono-hidratada ${ }^{10}$, contrariando a carga prevista postulada no modelo atual. Estudos cristalográficos envolvendo antagonistas $\mathrm{H}_{2}$ revelaram que o anel guanidinotiazólico, presente nos mais potentes antagonistas, não está protonado quando interage com ácidos orgânicos ${ }^{11}$, como postulado no presente modelo. $\mathrm{O}$ íon $\mathrm{AH}^{+}$, usado como um sítio doador de prótons, mostrou-se incompatível como um sítio de interação para histamina no receptor histaminérgico $\mathrm{H}_{2}$, como foi demonstrado pelo uso de modelagem molecular $^{4,7}$ e por QSAR-3D, descrita para outra classe de agonistas as imidazolilpropilguanidinas ${ }^{12}$. Ainda no presente modelo, o sítio de interação dos antagonistas na forma protonada é o mesmo sítio de interação da histamina, o que contraria os estudos farmacológicos efetuados por Krielaart et al., que sugerem um bloqueio da ação da histamina por seus antagonistas em sítios diferentes ${ }^{13}$. Importa considerar ainda, que o estudo de difusão da cimetidina na membrana de células de Caco-2 revelou que o transporte deste composto na forma desprotonada é 30 vezes mais rápido do que na forma protonada ${ }^{14}$. Em resumo, os dados referentes à carga dos antagonistas $\mathrm{H}_{2}$, os respectivos sítios de interação e o mecanismo de bloqueio não são compatíveis com os dados cristalográficos dos ligantes, com a estrutura 3D do receptor, com os dados farmacológicos do mecanismo de ação e com a natureza físico-química dos ligantes no processo de transporte, respectivamente. Portanto, é coerente admitir que os antagonistas $\mathrm{H}_{2}$ bloqueiem a ação da histamina na forma desprotonada, como também 
sugerido por Bastiaans et al. ${ }^{15}$ para os antagonistas $\mathrm{H}_{2}$, e por Stark et al. ${ }^{16}$ para os antagonistas $\mathrm{H}_{3}$.

No presente trabalho, é apresentado o cálculo das constantes de afinidade de dois sítios do receptor $\mathrm{H}_{2}$ para dezesseis compostos e suas naturezas químicas são determinadas via validações laterais ${ }^{17,18}$ de QSARs-3D, analisando assim, os sítios que interagem com as duas subunidades estruturais presentes nos antagonistas $\mathrm{H}_{2}$ - o grupo denominado "equivalente à uréia" e o anel heterocíclico substituído. Um novo mecanismo de ação é sugerido para estes compostos na conformação estendida e na forma desprotonada, no receptor $\mathrm{H}_{2}$ do átrio cardíaco. Validações estatísticas ${ }^{19}$ são consideradas para conferir uma maior robustez ao modelo e a análise comparativa dos campos moleculares - CoMFA - é feita para caracterizar a ambiência química global em torno dos antagonistas $\mathrm{H}_{2}$.

\section{PARTE EXPERIMENTAL}

\section{Materiais e métodos}

As constantes de dissociação dos antagonistas, $\mathrm{K}_{\mathrm{B}}(\mathrm{em} \mathrm{M})$, utilizadas neste trabalho, foram determinadas por Shankley et al. ${ }^{20}$.

As estruturas tridimensionais dos antagonistas $\mathrm{H}_{2}$ foram geradas na conformação estendida e na forma desprotonada, através do programa Sybyl ${ }^{21}$ v.6.5.3, e as distâncias entre as duas subunidades constituintes de todos os antagonistas estudados foram determinadas usando o mesmo programa. As cargas foram calculadas através do método Gasteiger implementado no programa Sybyl.

Os valores dos descritores de superfície molecular para os dezesseis antagonistas considerados e o número de fragmentos $-\mathrm{NH}_{2}$ presentes na estrutura destes compostos, foram obtidos através do programa TSAR - $3 \mathrm{D}^{22}$. Os valores de similaridade química foram obtidos após o alinhamento dos compostos segundo o critério de massa molar, usando o módulo ASP do programa TSAR - 3D. As estruturas alinhadas são mostradas na Figura 1. No tocante aos dados de similaridade química gerados, o módulo ASP contido no programa TSAR atribui o valor arbitrário de 1.000 à molécula tomada como referência. Os valores calculados de todos os descritores 2D e 3D utilizados neste trabalho são mostrados nas Tabelas 1 e 2 .

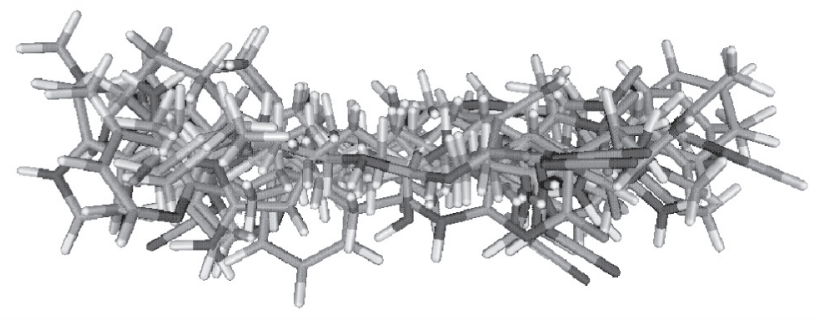

Figura 1. Estruturas alinhadas pelo critério de massas molares

Os coeficientes de adsorção dos antagonistas $\mathrm{H}_{2}, \mathrm{~K}_{\text {ads }}$ dado em $\mathbf{M}^{-1}$ (ver Tabela 2), foram calculados segundo a Equação descrita por Bushelev ${ }^{23}$ :

$\mathrm{K}_{\mathrm{ads}} \cdot \mathrm{K}_{\mathrm{B}}=\beta \cdot \exp .-\beta$

onde $\beta$ é o número de moléculas com superfície $S_{L}\left(\AA^{2}\right)$ adsorvidas numa superfície $S_{r}$ do receptor, dada por $S_{r}=\pi r^{2}$ em $\AA^{2}$, r é a distância entre duas $\alpha$ hélices que encerram os sítios receptores, aqui considerada igual a $10 \AA$, conforme dados da estrutura 3D dos GPCRs ${ }^{24}$. Os valores de $\beta$ são calculados mediante a Equação 2,

$\beta=\pi r^{2} / S_{L}$
Tabela 1. Estrutura e valores das potências e superfície moleculares dos compostos estudados

\begin{tabular}{|c|c|c|}
\hline $\mathrm{N}^{\circ}$. Composto & $\mathrm{pK}_{\mathrm{p}}$ & $S\left(\AA^{2}\right)$ \\
\hline
\end{tabular}

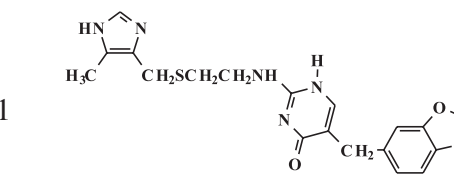

380,02

2

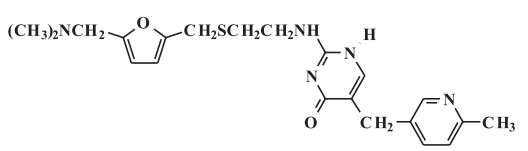<smiles>CC1(c2ccccc2)CC1</smiles><smiles>NCCCCc1csc(CN([NH3+])[15NH])c1</smiles>

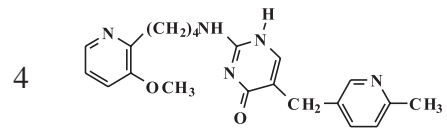

5

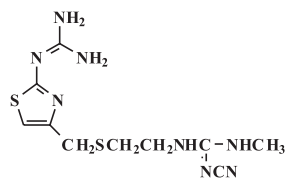

6

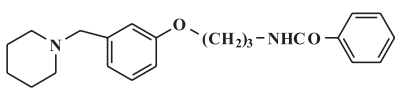

7

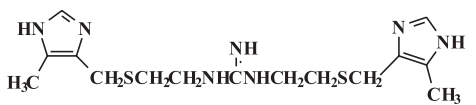

8

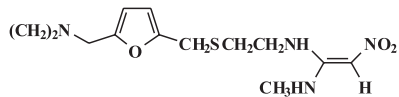

9

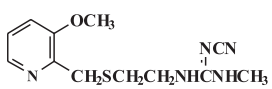

10
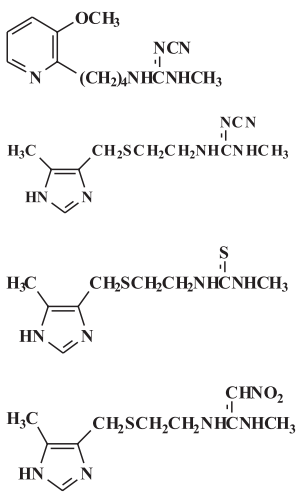

$\llbracket \underset{\mathrm{N}}{\mathrm{S}}-\mathrm{CH}_{2} \mathrm{SCH}_{2} \mathrm{CH}_{2} \mathrm{NHCNHCH}_{3}$

15

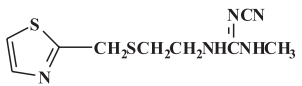

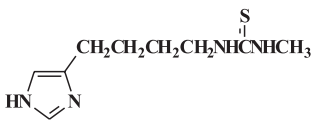


Tabela 2. Valores de potência, logaritmo do coeficiente de adsorção*, logaritmo negativo das constantes de afinidade dos sítios primário ( $\mathrm{K}_{1}$ ) e secundário $\left(\mathrm{K}_{2}\right)$, Similaridade combinada**, Similaridade de forma*** e descritor de superfície molecular, respectivamente, dos antagonistas $\mathrm{H}_{2}$. Os valores dados entre parêntesis são os logaritmos negativos das constantes de afinidade dos sítios primário e secundário, calculados por Krieelart et al. (ver ref. 13)

\begin{tabular}{llllllll}
\hline$N^{\circ}$ & $\mathrm{pK}_{\mathrm{B}}$ & $\log \mathrm{K}_{\mathrm{ads}}$ & $\mathrm{pK}_{1}$ & $\mathrm{pK}_{2}$ & $\mathrm{~S}_{\mathrm{c}<16>}$ & $\mathrm{S}_{\mathrm{f}<14>}$ & $\mathrm{K}_{\alpha 1}$ \\
\hline 1 & 7,05 & 6,61 & 7,31 & 5,70 & 0,166 & 0,550 & 19,188 \\
2 & 7,67 & 7,19 & 7,89 & 6,29 & 0,168 & 0,527 & 21,605 \\
3 & 7,74 & 7,31 & $8,00(8,00)$ & $6,41(6,5)$ & 0,103 & 0,639 & 17,292 \\
4 & 7,22 & 6,78 & 7,48 & 5,87 & 0,073 & 0,567 & 20,006 \\
5 & 7,57 & 7,14 & 7,84 & 6,24 & 0,259 & 0,643 & 16,833 \\
6 & 7,44 & 7,00 & 7,70 & 6,10 & 0,277 & 0,500 & 18,771 \\
7 & 7,24 & 6,80 & 7,50 & 5,89 & 0,213 & 0,571 & 19,356 \\
8 & 6,75 & 6,32 & $7,02(6,9)$ & $5,42(5,0)$ & 0,327 & 0,628 & 18,339 \\
9 & 6,66 & 6,23 & 6,93 & 5,33 & 0,470 & 0,666 & 15,597 \\
10 & 6,00 & 5,56 & 6,23 & 4,65 & 0,418 & 0,664 & 15,248 \\
11 & 6,08 & 5,64 & $6,34(6,5)$ & $4,73(4,3)$ & 0,399 & 0,807 & 15,863 \\
12 & 6,06 & 5,62 & 6,32 & 4,71 & 0,443 & 0,720 & 12,798 \\
13 & 5,34 & 4,91 & 5,61 & 4,01 & 0,381 & 0,883 & 14,999 \\
14 & 5,30 & 4,86 & 5,56 & 3,95 & 0,427 & 1,000 & 14,650 \\
15 & 5,85 & 5,41 & 6,11 & 4,50 & 0,469 & 0,890 & 13,515 \\
16 & 4,92 & 4,46 & 5,16 & 3,56 & 1,000 & 0,739 & 11,455
\end{tabular}

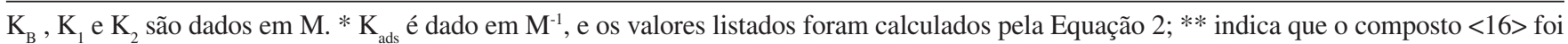
tomado como referência; $* * *$ denota que o composto $<14>$ foi tomado como referência, conforme notação do programa ASP. Ver texto para maiores detalhes.

As constantes de afinidade dos sítios primário e secundário foram determinadas graficamente na relação descrita por $\log \mathrm{C}$ versus $\mathrm{K}_{\mathrm{ads}} \cdot \mathrm{C}$, onde $\mathrm{C}$ é a concentração ativa dos antagonistas $\mathrm{H}_{2}$. A concentração é variada na faixa correspondente à janela terapêutica e o produto $\mathrm{K}_{\mathrm{ads}} \cdot \mathrm{C}$ é determinado nesta faixa de concentração. Nos pontos onde ocorrem mudanças na inflexão da curva do gráfico de $\log \mathrm{C}$ versus $\mathrm{K}_{\mathrm{ads}} . \mathrm{C}$, as constantes de afinidade são determinadas para os sítios primário e secundário. Onde ocorre a primeira mudança de inflexão, ou seja em $\mathrm{K}_{\mathrm{ads}} \cdot \mathrm{C}=0,2$, o valor calculado de $\mathrm{C}$ identifica-se com o valor da constante de afinidade do sítio primário, $\mathrm{K}_{1}$ expressa em $\mathrm{M}$. A segunda mudança de inflexão ocorre em $\mathrm{K}_{\mathrm{ads}} \cdot \mathrm{C}=8$ e $\mathrm{C}$ identifica-se com o valor da constante de afinidade do sito secundário, com $\mathrm{K}_{2}$ dada igualmente em M. A Figura 2 mostra o gráfico de $\log \mathrm{C}$ versus $\mathrm{K}_{\text {ads }} . \mathrm{C}$ para o mais potente antagonista. Os valores das constantes de afinidade do sítio primário e secundário calculados são dados na Tabela 2 , como logaritmo negativo das constantes de afinidade dos respectivos sítios. Os valores dados entre parênteses são aqueles determinados por Krielaart et al. ${ }^{13}$ para três antagonistas: famotidina (composto 3 na Tabela 2), ranitidina (composto 8 na Tabela 2) e cimetidina (composto 11 na Tabela 2), cujo método é dado a seguir.

O método ${ }^{13}$ usado por Krielaart et al. consiste na simulação da isoterma de interação da histamina na presença de um antagonista descrita pela relação:

$\mathrm{f}=a . i . /\left[1+[\mathrm{A}] / \mathrm{K}_{4}+\mathrm{K}_{1} /[\mathrm{L}]\left\{1+[\mathrm{A}] / \mathrm{K}_{3}\right\}\right] \cdot \mathrm{q}$

onde f é a resposta biológica parcial, obtida a partir dos valores de aumento da freqüência de batimentos cardíacos promovidos pelo agonista; $a . i$ é a atividade intrínseca do agonista no tecido $(0<a . i$. $>$ $1) ; K_{1}$ é a constante de dissociação do agonista; $K_{3}$ é a constante de afinidade do sítio primário; $\mathrm{K}_{4}$ é a constante de afinidade do sítio secundário; q é a reserva de receptores dada por [RL] / [R ] ; $R L]$ é a concentração do agonista complexada e $\left[R_{t}\right]$ é a concentração total de receptores. As concentrações dos antagonistas [A] são dadas em $\mathrm{M}$, bem como as constantes de afinidade.

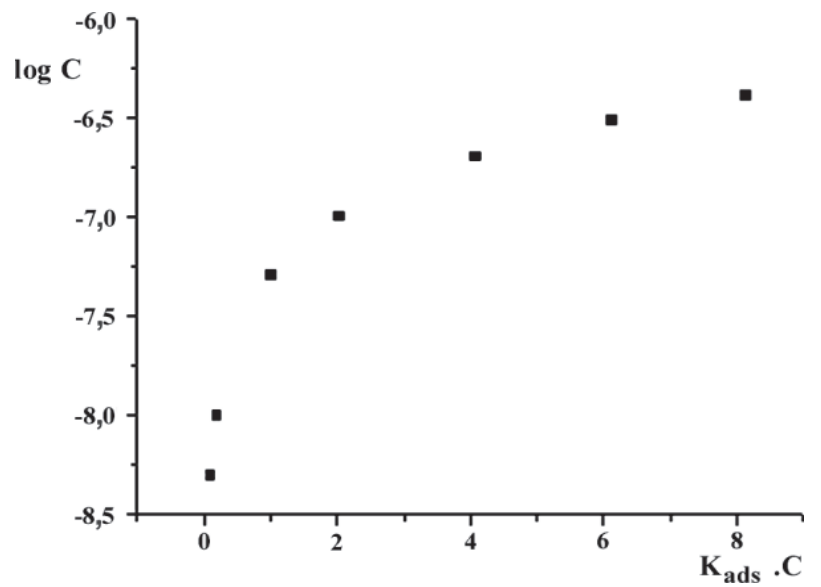

Figura 2. Gráfico de $\log C$ versus $K_{a d s^{\circ}} C$ para o mais potente antagonista. $O$ valor de $K_{\text {ads }}$ usado é mostrado na Tabela 2 como $\log K_{a d s}$. A faixa de variação de $C$ corresponde àquela da janela terapêutica: de $5 \times 10^{-9} \mathrm{M}$ a $4 \times 10^{-7} \mathrm{M}$. A primeira mudança de inclinação ocorre em $K_{\text {ads }} \mathrm{C}=0,20$ e a segunda mudança em $K_{a d s}$. C = 8,0. A adsorção dos antagonistas $\mathrm{H}_{2} e ́$ governada por dois sítios quimicamente idênticos

Na simulação do efeito do inibidor, a Equação 2a considera que a presença do antagonista no sítio secundário não afeta a interação do agonista e vice-versa. Isto equivale a dizer que o comportamento do receptor no estado ativado é similar ao comportamento no estado de repouso, quer na presença do agonista ou do antagonista, ou na presença dos dois conjuntamente. Note que a Equação 2a considera que apenas dois sítios antagonistas são relevantes na descrição do processo de bloqueio do agonista, mas não foi feita uma identificação química destes sítios, bem como uma descrição da afinidade destes por fragmentos moleculares específicos presentes na estrutura dos antagonistas. Isto torna relevante a análise das interações por 
QSAR para uma série relativamente grande de compostos contendo uma diversidade química de grupos funcionais.

A análise comparativa dos campos moleculares estéreos e eletrostáticos, CoMFA, foi obtida pelo programa Sybyl12, operando uma estação de trabalho Silicon Graphics O2. Na determinação da correlação entre os valores preditos e calculados, as constantes de dissociação dos antagonistas foram consideradas para a análise da validação estatística do modelo.

Estas análises tornam-se mais relevantes quando existem dois modelos distintos para o mecanismo de bloqueio do receptor histaminérgico $\mathrm{H}_{2}$. No modelo atual ${ }^{8}$, um antagonista bloqueia a ação da histamina ligando-se nos mesmos sitos de interação desta; no segundo modelo ${ }^{4}$ o antagonista pode bloquear os resíduos protéicos transmissores de prótons necessários à ativação da proteína $\mathrm{G}_{\alpha}$.

\section{RESULTADOS E DISCUSSÃO}

O alinhamento dos antagonistas na forma desprotonada e na conformação estendida efetuada pelo critério de massa molar, como mostrado na Figura 1, é pertinente para a verificação da hipótese da adsorção dos antagonistas ser governada por dois sítios receptores quimicamente equivalentes envolvidos numa possível bomba de prótons, pois a disposição dos ligantes alinhados, segundo este critério, apresenta os anéis substituídos com fragmentos moleculares nitrogenados em posições opostas. Este alinhamento é compatível com os dados cristalográficos dos mais seletivos antagonistas ${ }^{10,11}$, com o mecanismo proposto para a bomba de prótons no receptor $\mathrm{H}_{2}$, e com a correlação entre os logaritmos negativos das constantes de afinidade $\mathrm{pK}_{1}$ e $\mathrm{pK}_{2}$, dada pela Equação $2 \mathrm{~b}$, que sugere uma similaridade química entre dois sítios receptores. Portanto,

$\mathrm{pK}_{1}=1,020( \pm 0,027) \mathrm{pK}_{2}+1,522( \pm 0,142)$

$\left(\mathrm{n}=16 ; \mathrm{r}^{2}=0,990 ; \mathrm{SD}=0,094\right)$

Importa considerar no presente momento que a Equação 2b sugere a inclusão de antagonistas com uma cadeia molecular extensa para o estudo das QSARs-3D com o critério de alinhamento das estruturas por massas molares, pois possibilita o estudo de um possível bloqueio da bomba de prótons, efetuado pelo afastamento dos grupos protéicos responsáveis pelo transporte de prótons em diferentes hélices.

Uma análise comparativa dos valores de $\mathrm{pK}_{\mathrm{B}}$, do logaritmo do coeficiente de adsorção e das constantes de afinidade mostrados nas Tabelas 1 e 2 sugere que uma grande superfície molecular e a presença de fragmentos $-\mathrm{NH}_{2}$ presentes na estrutura dos antagonistas respondem pela eficiência destes. Inversamente, antagonistas contendo anéis imidazólicos que podem ativar uma transferência de prótons pelo seu caráter tautomérico são fracamente adsorvidos e promovem um decréscimo na afinidade pelos dois sítios. Isto sugere que estes possam ser quimicamente equivalentes.

A coerência da metodologia proposta para a determinação das constantes de afinidade dos sítios primário e secundário pode ser vista na Tabela 2, que encerra os dados comparativos das constantes de afinidade calculados pelos dois métodos. Estas análises mostram que os valores das constantes de afinidade para ambos os sítios se aproximam quanto mais potente é o antagonista, como mostrado para o mais potente antagonista da série estudada. As constantes de afinidade para o sítio primário são iguais $\left(\mathrm{pK}_{1}=8\right)$ para os dois métodos, e para o sítio secundário são ligeiramente diferentes: $\mathrm{pK}_{2}=6,5$ para este trabalho, e igual a 6,41 conforme Krielaart et al. ${ }^{13}$. Isto leva-nos a concluir que a adsorção é regulada por dois sítios, e o coeficiente de adsorção é uma medida quantitativa da seletividade de um estado conformacional protéico específico para os antagonistas $\mathrm{H}_{2}$, presentes na forma desprotonada e na conformação estendida.
Uma análise conjunta dos valores de $\mathrm{pK}_{1}$ e da superfície molecular dos antagonistas indica que compostos contendo anéis aromáticos de cinco ou seis membros nitrogenados, ou aromáticos ligados a um grupo amino possuem uma grande afinidade pelo sítio receptor primário, como mostrado na Equação 3. A planaridade dos anéis sugere a presença de resíduos protéicos contendo anéis aromáticos, formando a cavidade do receptor $\mathrm{H}_{2}$ e o aumento da afinidade pelo sítio primário devido aos fragmentos $-\mathrm{NH}_{2}$, indica o caráter hidroxílico este sítio. Esta é uma característica básica das cavidades formadas pelas hélices 5 e 6 dos $\mathrm{GPCR}^{25}$. A afinidade pelo sítio primário aumenta também devido à presença de fragmentos $-\mathrm{NH}_{2}$ na estrutura do antagonista, cujo número de fragmentos é descrito pelo parâmetro NF. Portanto,

$\mathrm{pK}_{1}=0,014( \pm 0,002) \mathrm{S}_{\mathrm{M}}+0,395( \pm 0,187) \mathrm{NF}+2,038$

$\left(\mathrm{n}=16 ; \mathrm{r}^{2}=0,862 ; \mathrm{s}=0,414 ; \mathrm{r}_{\mathrm{cv}}^{2}=0,830\right)$

$\mathrm{O}$ valor positivo do coeficiente angular do parâmetro $\mathrm{S}_{\mathrm{M}}$ na Equação 3 sugere que o resíduo protéico formador deste sítio está direcionado para o interior de uma grande cavidade formada por $\alpha$ hélices, onde as restrições estéreas são pequenas relativamente ao plano do anel do antagonista. Se considerarmos ainda, que a distância máxima entre as duas prováveis hélices seja igual à distância entre os fragmentos $-\mathrm{NH}_{2}$ do grupo equivalente à uréia e do anel heterocíclico do mais potente antagonista estudado, isto é, 14,7 , então este valor aqui obtido é similar àquele descrito para a distância máxima entre as hélices 5 e 6 no receptor $\beta_{2}$-adrenérgico ${ }^{24}(15 \AA)$, quando interage com seus agonistas e antagonistas. Este valor foi determinado por modelagem molecular. Isto significa que a hélice 5 no receptor $\mathrm{H}_{2}$ possui uma relativa mobilidade. Note que no modelo da bomba de prótons do receptor histaminérgico ${ }^{4} \mathrm{H}_{2}$ ocorre uma transferência de prótons entre as hélices 5 e 6 e, se estas hélices se afastam, então uma transferência de prótons promovida pelo agonista (histamina) é improvável.

As características estruturais dos antagonistas que impedem a interação com o sítio primário podem ser inferidas a partir dos pequenos valores de $\mathrm{pK}_{1}$ e são representadas pelos grupos 3,4-diaminonitroeteno, imidazólico, tiazólico e uréia. No primeiro, o subgrupo nitro interage com fragmento -NH- da cadeia lateral via ligação hidrogênio, impedindo a interação deste subgrupo com o sítio receptor. Nos demais grupos contendo enxofre, as ligações C-S, C=S, os átomos de enxofre são bases de Lewis fracas nas interações com grupos doadores de prótons em ligações hidrogênio, e o anel imidazólico pode ativar grupos doadores de prótons devido ao seu caráter tautomérico ${ }^{16}$. Estas características sugerem que os grupos ativos dos antagonistas interajam com um resíduo fenólico, pois estes possuem uma pequena afinidade com os fragmentos $-\mathrm{NO}_{2}, \mathrm{C}-\mathrm{S}$ e $\mathrm{C}=\mathrm{S}$, como verificado por Abraham et al. ${ }^{26}$, e pode ser ativado pelo anel imidazólico ${ }^{16,26}$. Nossos dados mostram que os valores de $\log \mathrm{K}_{1}$ constituem um bom critério para o planejamento racional dos antagonistas $\mathrm{H}_{2}$ capazes de interagir com grupos doadores de prótons nos GPCR.

As características acima podem ser verificadas de uma forma quantitativa na correlação entre $\mathrm{pK}_{1}$ e a similaridade química combinada (de carga e forma), considerando o menos potente antagonista como referência. Note que este composto possui uma ligação $\mathrm{C}=\mathrm{S}$, onde o enxofre é um fraco receptor de prótons, e possui um anel imidazólico que pode ativar transferência de prótons em grupos protéicos hidroxílicos ${ }^{16,26}$. Portanto

$\mathrm{pK}_{1}=-4,506( \pm 0,458) \mathrm{S}_{\mathrm{c}<16>}+9,22$

$\left(\mathrm{n}=16 ; \mathrm{r}^{2}=0,621 ; \mathrm{s}=0,628 ; \mathrm{r}_{\mathrm{cv}}^{2}=0,608\right)$ 
É provável que o sítio primário do receptor $\mathrm{H}_{2}$ seja uma tirosina, porque o coeficiente angular da Equação 4 é similar ao coeficiente angular da Equação 5 determinada por Abraham et al. ${ }^{26}$, que descreve a interação de aminas, heterocíclicos nitrogenados (exceto 2piridina), éteres e oximas com 4-nitrofenol como doador de prótons em ligação hidrogênio

$\log \mathrm{K}_{\beta}=4,44( \pm 0,23) \beta_{\mathrm{sm}}-0,52( \pm 0,15)$

$\left(\mathrm{n}=31 ; \mathrm{r}^{2}=0,930 ; \mathrm{s}=0,20 ; \mathrm{F}=382\right)$

onde $\mathrm{K}_{\beta}$ é a constante de equilíbrio e $\beta_{\mathrm{sm}}$ caracteriza a base. Na determinação deste último parâmetro, os termos translacionais foram removidos, e $\beta_{\mathrm{sm}}$ é proporcional a $\Delta \mathrm{H}$ interação ácido - base. Portanto, pode ser visto que os parâmetros $S_{c<16>}$ e $\beta_{s m}$ são proporcionais.

Grande parte das características mencionadas anteriormente está presente na cavidade hidrofóbica formada pelas hélices 5 e 6 do receptor $\mathrm{H}_{2}$, conforme o modelo de Hibert et al. ${ }^{25}$, como mostrado na Figura 3, a saber:

1 - Esta hélice possui um resíduo de tirosina e, portanto, é portadora de um grupo fenol direcionado para uma cavidade central ${ }^{1,2,25}$.

2 - A tirosina da hélice 5 está próxima à fase extracelular ${ }^{2,4}$ podendo estar ativada e interagir favoravelmente com bases nitrogenadas ${ }^{4}$ na forma neutra, ou abstrair prótons de bases nitrogenadas protonadas na forma ionizada, através do íon fenolato ${ }^{4}$.

3 - O grupo fenólico é volumoso, podendo apresentar múltiplas interações com outros anéis aromáticos, como mostrado no receptor histaminérgico $\mathrm{H}_{3}{ }^{16}$.

4 - A cavidade formada por estas duas tirosinas é grande podendo acomodar ligantes volumosos ${ }^{25}$, e a distância entre as hélices 5 e 6 nos GPCR $^{24}$ (de 10 a $17 \AA ̊$ ) é compatível com a distância entre os grupos $-\mathrm{NH}_{2}$ terminais, na estrutura do mais potente antagonista que é de $14,7 \AA$.

$\mathrm{Na}$ tentativa de confirmar a natureza fenólica do sítio primário e o grau de impedimento estéreo em torno deste, tentou-se uma correlação entre a constante de afinidade do sítio primário, $\mathrm{pK}_{1}$, e os descritores de similaridade combinada, tomando o composto 16 como

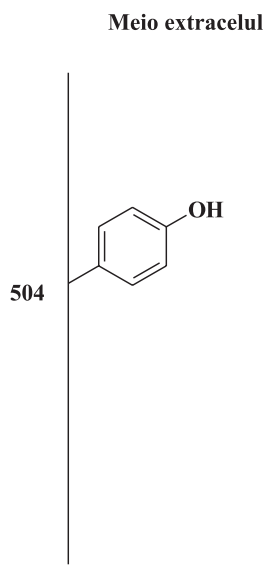

Hélice 5

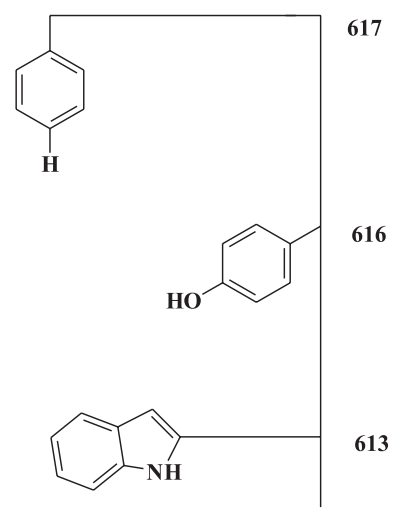

Hélice 6
Meio intracelular

Figura 3. Resíduos de aminoácidos e suas posições relativas nas hélices 5 e 6 formando uma cavidade hidrofóbica no receptor $\mathrm{H}_{2}$, segundo o modelo $3 D$ global proposto por Hibert et al. para os GPCRs (ver ref. 25). No modelo da bomba de prótons do receptor $\mathrm{H}_{2}$ as tirosinas 504 (quarta posição na hélice 5) e 616 (décima sexta posição na hélice 6) estão envolvidas no transporte de prótons referência, $\mathrm{S}_{\mathrm{c}(16)}$, e similaridade de forma, considerando o composto 14 como composto líder, $S_{\mathrm{f}(14)}$, por possuírem pequena afinidade pelo sítio primário. A relação obtida mostra que os grupos sulfurados ou oxigenados, descritos pelo termo de similaridade de forma, diminuem a afinidade pelo sítio primário de acordo com a Equação:

$\mathrm{pK}_{1}=-3,006( \pm 0,800) \mathrm{S}_{\mathrm{c}(16)}-3,420( \pm 0,813) \mathrm{S}_{\mathrm{f}(14)}+10,770$

$\left(\mathrm{n}=16 ; \mathrm{r}^{2}=0,845 ; \mathrm{s}=0,441 ; \mathrm{r}_{\mathrm{cv}}^{2}=0,806\right)$

Numa análise comparativa entre o coeficiente do termo de similaridade de forma na Equação 6, e do coeficiente do termo de basicidade $\beta_{\mathrm{sm}}$ na Equação 7, determinada por Abraham et al. ${ }^{26}$, vemos que são similares. Esta última equação descreve a interação de 8 bases oxigenadas com 4-fluorofenol,

$\log \mathrm{K}_{\beta}=3,65(0,33) \beta_{\mathrm{sm}}-0,46(0,14)$

$\left(\mathrm{n}=8 ; \mathrm{r}^{2}=0,995 ; \mathrm{s}=0,11 ; \mathrm{F}=125\right)$

onde $\mathrm{K}_{\beta}$ é a constante de equilíbrio. Estes dados sugerem novamente que o sítio primário é uma tirosina fortemente ativada, onde o resíduo fenólico interage fortemente com os nitrogênios $\mathrm{sp}^{3}$ ou sp $\mathrm{sp}^{2}$ ligados a carbono nos antagonistas e, fracamente, com os átomos de oxigênio ligados a nitrogênio presentes na estrutura destes ligantes.

No tocante ao sítio secundário, a Tabela 2 mostra que os compostos 13,14 e 16 podem ser considerados inativos em relação a este sítio e, portanto, podem ser tomados como referências para o estudo de similaridade química ou QSAR-3D, quer separada ou conjuntamente.

A QSAR-3D correlacionando a afinidade do sítio secundário, $\mathrm{pK}_{2}$, com a similaridade combinada tomando o menos potente antagonista como referência, mostra que o coeficiente angular da Equação 8 é similar aos coeficientes angulares das Equações 4 e 5, como previamente mostrado, sugerindo que este outro sítio é formado também por uma tirosina. Este dado é compatível com os dados de afinidade mostrados na Tabela 2, bem como com o modelo 3D proposto por Hibert et al. ${ }^{25}$ contendo os possíveis sítios de interação para os antagonistas $\mathrm{H}_{2}$ nas hélices 5 e 6, mostrados na Figura 3. Portanto,

$\mathrm{pK}_{2}=-4,501( \pm 0,448) \mathrm{S}_{\mathrm{c}(16)}+7,816$

$\left(\mathrm{n}=16 ; \mathrm{r}^{2}=0,618 ; \mathrm{s}=0,630 ; \mathrm{r}_{\mathrm{cv}}^{2}=0,604\right)$

Como discutido anteriormente, a inatividade do composto 16 em relação ao sítio secundário indica a pequena afinidade deste sítio pela uréia substituída, devido à ligação $\mathrm{C}=\mathrm{S}$, e pelo fato do anel imidazólico ativar grupos doadores de prótons como tirosinas, devido à sua atividade tautomérica ${ }^{4}$.

A natureza fenólica do segundo sítio pode ser confirmada pelo valor $\Delta \Delta \mathrm{G}_{2}$ obtido a partir da Equação 8, como sugerido pelos estudos de modelagem molecular para o receptor $\beta$-adrenérgico na interação com seus antagonistas e agonistas ${ }^{27}$. Segundo este estudo, os antagonistas promovem um aumento na barreira de ativação dos grupos doadores de prótons e o valor de $\Delta \Delta \mathrm{G}$ dos antagonistas é uma medida deste aumento. No presente estudo, da barreira de ativação obtida a partir da Equação $8, \Delta \Delta \mathrm{G}_{2}=2,3 \mathrm{RT}(7,816-3,56)$ é igual a $6,04 \mathrm{kcal} \mathrm{mol}^{-1}$, sendo 3,56 o valor de $\mathrm{pK}_{2}$ do menos potente antagonista e RT $=0,617 \mathrm{kcal}_{\mathrm{mol}}{ }^{-1}$. Este valor é similar ao da energia de ativação de uma tirosina envolvida numa bomba de prótons no receptor $\beta$-adrenérgico (entre $5,0 \mathrm{kcal} \mathrm{mol}^{-1}$ e 7,0 $\mathrm{kcal} \mathrm{mol}^{-1}$ ), conforme estudos de modelagem molecular ${ }^{27,28}$. Isto confirma que $\mathrm{o}$ sítio secundário é também uma tirosina, mas localizada numa região com impedimento estéreo. Este resíduo fenólico interage com os nitrogênios $\mathrm{sp}^{3}$ ou $\mathrm{sp}^{2}$ ligados a carbono nos antagonistas e, fracamente, com os átomos de oxigênio presentes na estrutura destes. No 
modelo da bomba de prótons, uma tirosina na hélice 6 está igualmente envolvida no transporte deste íon ${ }^{4}$. Note que o sítio secundário está envolvido na ativação da adenilato ciclase ${ }^{13}$ via proteína ${ }^{4} G_{\alpha}$.

Numa outra tentativa de confirmar a natureza fenólica do sítio secundário, foi feita uma correlação entre os valores de $\mathrm{pK}_{2} \mathrm{e}$ os de similaridade de forma (com o composto 14 como referência) e similaridade combinada (com o composto 16 como referência). A Equação 9 correspondente confirma que este sítio possui pouca afinidade por grupos oxigenados e o coeficiente angular do termo de similaridade de forma $\left(\mathrm{S}_{\mathrm{f}}\right)$ é similar ao coeficiente angular do parâmetro $\beta_{\mathrm{sm}}$ da Equação 7, confirmando a natureza fenólica deste sítio, como mostrado:

$\mathrm{pK}_{2}=-3,428( \pm 0,811) \mathrm{S}_{\mathrm{f}<14>}-3,002( \pm 0,805) \mathrm{S}_{\mathrm{c}<16>}+9,171$

$\left(\mathrm{n}=16 ; \mathrm{r}^{2}=0,845 ; \mathrm{s}=0,441 ; \mathrm{r}_{\mathrm{cv}}{ }^{2}=0,805\right)$

No tocante aos grupos que mostram alta afinidade pelo sítio secundário, temos os grupos detentores de fragmentos $-\mathrm{NH}_{2}$ como os grupo $\left(\mathrm{H}_{2} \mathrm{~N}\right)_{2} \mathrm{C}=\mathrm{N}$ - ligados ao anel tiazólico, o substituinte $-\mathrm{SO}_{2} \mathrm{NH}_{2}$ e podem ser descritos pelo parâmetro NF na Equação 10. Os compostos detentores de grupos aromáticos, como por exemplo, o anel $-\mathrm{OC}_{6} \mathrm{H}_{5}$ e furânico adjacentes a uma amina terciária, conferem um aumento de superfície molecular aos antagonistas e aumentam a afinidade pelo sítio secundário de acordo com a equação:

$\mathrm{pK}_{2}=0,014( \pm 0,002) \mathrm{S}_{\mathrm{M}}+0,398( \pm 0,188) \mathrm{NF}+0,708$

$\left(\mathrm{n}=16 ; \mathrm{r}^{2}=0,862 ; \mathrm{s}=0,415 ; \mathrm{r}^{2}{ }_{\mathrm{cv}}=0,828\right)$

$\mathrm{O}$ fragmento $-\mathrm{C}=\mathrm{NSO}_{2} \mathrm{NH}_{2}$ presente no mais potente antagonista apresenta características estruturais semelhantes ao fragmento $-\mathrm{CH}_{2} \mathrm{SO}_{2} \mathrm{~N}\left(\mathrm{CH}_{3}\right)_{2}$ que aumenta a potência dos antagonistas $\beta$-adrenérgicos, quando ligado na posição meta no anel aromático, portanto, numa posição terminal ${ }^{29}$. Similarmente, o anel $-\mathrm{OC}_{6} \mathrm{H}_{5}$ substituído também aumenta a potência dos antagonistas $\beta$-adrenérgicos quando posicionado na cadeia terminal ligada a um nitrogênio amínico $^{29}$. Note que o modelo de ativação do receptor $\beta$ - adrenérgico envolve uma transmissão de prótons neste receptor com a participação e um agonista tem sido postulado ${ }^{27,28}$. Os nossos resultados são coerentes com as relações estrutura-atividade de outros sistemas ${ }^{29}$, onde bomba de prótons é possível ${ }^{28}$.

No modelo proposto por Hibert ${ }^{25}$ para a formação da principal cavidade dos GPCR, os resíduos hidroxílicos nas hélices 5 e 6 têm um papel preponderante. Isto se deve à projeção destes resíduos protéicos para o interior da cavidade hidrofóbica, onde os fragmentos $-\mathrm{NH}_{2}$ presentes na estrutura do antagonista podem atuar como receptores de próton em ligação hidrogênio.

$\mathrm{Na}$ tentativa de caracterizar a natureza do resíduo que interage com os fragmentos $-\mathrm{NH}_{2}$ efetuou-se uma correlação entre os valores $\log \mathrm{K}_{\mathrm{ads}}$ com o descritor de superfície molecular, $\mathrm{K}_{\alpha 1}$, e com o número de fragmentos $-\mathrm{NH}_{2}$ presentes na estrutura dos antagonistas. $\mathrm{O}$ respectivo descritor de superfície considera a contribuição da superfície de cada átomo para a superfície molecular relativamente à superfície de um átomo de carbono $\mathrm{sp}^{3}$. A correlação obtida, mostrada na Equação 11, indica que a adsorção dos ligantes é facilitada quando estes possuem uma grande superfície molecular e um grande número de fragmentos $-\mathrm{NH}_{2}$. Portanto

$\log \mathrm{K}_{\mathrm{ads}}=0,358( \pm 0,068) \mathrm{NF}+0,296( \pm 0,034) \mathrm{K}_{\alpha 1}+1,94$

$\left(\mathrm{n}=16 ; \mathrm{r}^{2}=0,832 ; \mathrm{s}=0,410 ; \mathrm{r}_{\mathrm{cv}}^{2}=0,831\right)$

Uma análise comparativa do coeficiente angular do parâmetro NF na Equação 11 mostra que é similar à inclinação da Equação 12, que descreve a interação de aminas alifáticas (caracterizadas pelos valores de $\mathrm{pK}_{\mathrm{a}}$ ) com 4-nitrofenol como doador de prótons, como determinada por Abraham et al. ${ }^{26}$. Nesta equação, $\mathrm{K}_{\beta}$ é a constante de equilíbrio. Portanto

$\log \mathrm{K}_{\beta}=0,37( \pm 0,04) \mathrm{pK}_{\mathrm{a}}-1,08$

$\left(\mathrm{n}=5 ; \mathrm{r}^{2}=0,974 ; \mathrm{s}=0,14 ; \mathrm{F}=110\right)$

Através da analise comparativa dos coeficientes angulares dos parâmetros NF e pK é possível sugerir que a adsorção dos antagonistas é governada por resíduos de tirosinas presentes no receptor, pois se o número de fragmentos $-\mathrm{NH}_{2}$ aumenta, o valor de $\mathrm{pK}_{\mathrm{a}}$ também aumenta, possibilitando uma maior interação dos sítios de adsorção (sítios fenólicos) com estes fragmentos moleculares. Este resultado é compatível com as QSARs - 3D e suas validações.

\section{Análise dos campos moleculares eletrostáticos e estéreos, CoMFA}

Uma característica marcante na ambiência química em torno de agonistas ou antagonistas que se posicionam entre as hélices 5 e 6 no modelo dos GPCR é a presença de um anel aromático de uma fenilalanina perpendicular ao anel destes ligantes, segundo o modelo de Hibert ${ }^{25}$. A interação dos antagonistas com este resíduo da hélice 6 permite um bloqueio das mudanças conformacionais necessárias à ativação da proteína $G^{25}$. Note que nas hélices 5 e 6 existem tirosinas direcionadas para o interior de uma cavidade central onde agonistas ou antagonistas podem se posicionar.

Com a finalidade de avaliar a distribuição do campo eletrostático molecular em torno dos antagonistas $\mathrm{H}_{2}$ para inferir a possibilidade das duas subunidades estruturais dos antagonistas interagirem com uma fonte doadora de prótons, uma interação destes ligantes com a sonda $\mathrm{C}^{+}\left(\mathrm{sp}^{3}\right)$ foi estabelecida. Os resultados mostraram uma região contínua e favorável para a interação com esta sonda no espaço entre o fragmento $-\mathrm{NH}_{2}$ do grupo equivalente à uréia e o nitrogênio $\mathrm{sp}^{2}$ do grupo guanidínico ligado ao anel tiazólico do mais potente antagonista, cuja estrutura é mostrado na Figura 4. Uma distribuição desfavorável com esta sonda engloba a região em torno dos fragmentos $-\mathrm{NH}_{2}$ do grupo guanidinotiazólico do mais potente antagonista.

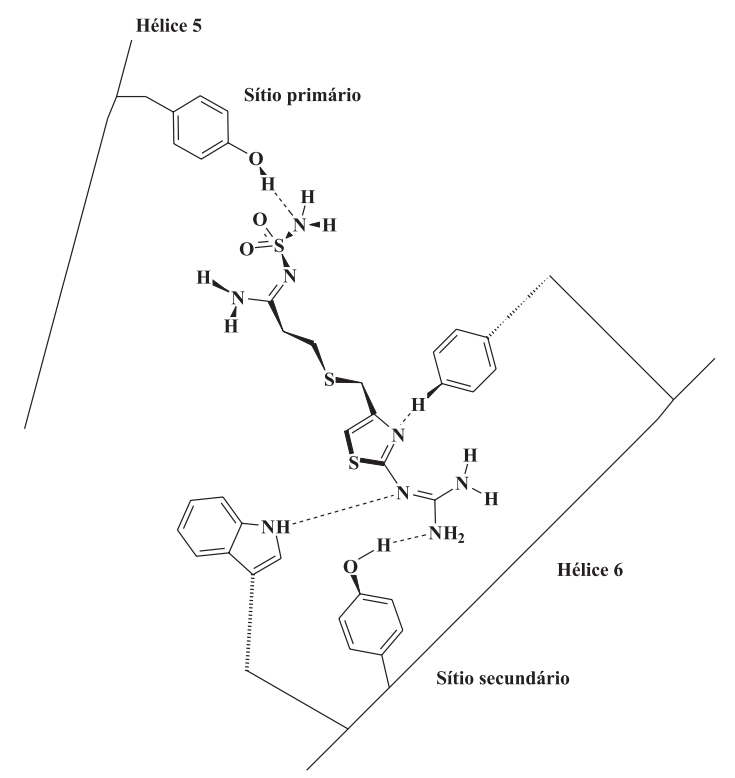

Figura 4. Ambiência química em torno do mais potente antagonista $\mathrm{H}_{2}$ na forma desprotonada e na conformação estendida, de acordo os dados de QSAR-3D e a análise comparativa dos campos moleculares estéreos e eletrostáticos 
Tendo em vista a possibilidade dos antagonistas interagirem com o resíduo aromático de uma fenilalanina e de um triptofano na hélice 6 , segundo o modelo proposto por Hibert ${ }^{25}$, interações entre estes ligantes e a sonda $\mathrm{C}_{\text {AROMÁtICO }}$ foram efetuadas. Os resultados mostraram um campo estéreo desfavorável na interação com esta sonda nas regiões perpendicular ao plano superior do anel tiazólico do mais potente antagonista, e paralela a este anel. Estes dados correspondem no modelo 3D de Hibert aos anéis aromáticos da fenilalanina 617 e do triptofano 613, como mostrado na Figura 4. As regiões favoráveis à interação com esta sonda correspondem ao espaço à esquerda do fragmento $-\mathrm{SO}_{2}$ do grupo equivalente à uréia do mais potente antagonista e à direita do grupo guanidínico ligado ao anel tiazólico, do mais potente antagonista.

Os campos moleculares eletrostáticos e estéreos foram gerados na condição padrão ("cutoffs" de $30 \mathrm{kcal} \mathrm{mol}^{-1}$ ) para as sondas de $\mathrm{C}^{+}$ $\left(\mathrm{sp}^{3}\right)$ e $\mathrm{C}_{\text {AROMÁtico }}$, onde os 16 compostos usados foram alinhados pelo critério de massas moleculares. Na geração do modelo estatístico o número de componentes principais foi igual a 6 , e este mostra $63 \%$ de caráter estéreo e $37 \%$ de caráter eletrostático. A Figura 5 mostra os campos moleculares estéreos e eletrostáticos em torno do mais potente antagonista, bem como a correlação entre os valores experimentais e calculados da potência dos antagonistas, na conformação estendida e na forma desprotonada.

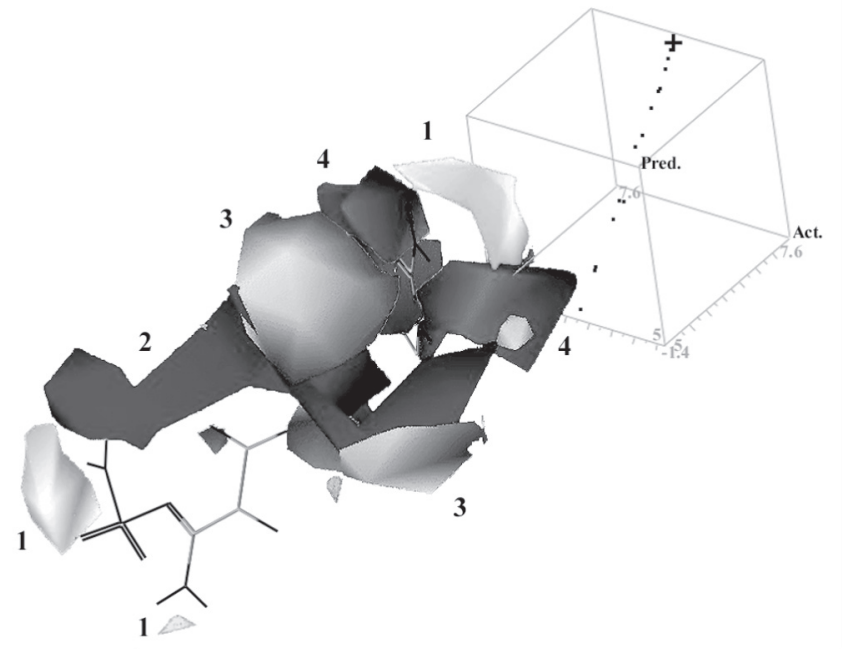

Figura 5. Correlação entre os valores experimentais e calculados de $p K_{B} e$ campos moleculares estéreos e eletrostáticos em torno do mais potente antagonista na conformação estendida e na forma desprotonada: 1 interação favorável com grupos volumosos; 2 - interação favorável com carga positiva; 3 - interação desfavorável com grupos volumosos e 4 interação desfavorável com carga positiva

Os parâmetros estatísticos derivados da correlação entre $\mathrm{pK}_{\mathrm{B}} \mathrm{e}$ as energias eletrostáticas de interação e repulsão obtidas da interação dos ligantes com a sonda $\mathrm{C}^{+}\left(\mathrm{sp}^{3}\right)$ mostram

$\mathrm{n}=16 ; \mathrm{r}^{2}=0,994 ; \mathrm{s}=0,082 ; \mathrm{F}=252,727 ; \mathrm{r}_{\mathrm{cv}}^{2}=0,581$

e revelam um bom caráter preditivo do modelo para os compostos na forma desprotonada e na conformação estendida.

Os parâmetros estatísticos derivados da correlação entre $\mathrm{pK}_{\mathrm{B}} \mathrm{e}$ as energias de interação e repulsão entre os ligantes e a sonda $\mathrm{C}_{\text {ARоми́тісо }}$ revelam, igualmente, uma boa predição do modelo para os ligantes na conformação estendida e na forma desprotonada.

$\mathrm{n}=16 ; \mathrm{r}^{2}=0,988 ; \mathrm{s}=0,082 ; \mathrm{F}=122,952 ; \mathrm{r}_{\mathrm{cv}}^{2}=0,581$
A distribuição dos campos estéreos em torno do mais potente antagonista (Figura 5) revela as características básicas do modelo de Hibert para os ligantes posicionados entre as hélices 5 e 6 - um campo demonstrando impedimento estéreo no plano perpendicular ao anel do ligante (representado pelo anel tiazólico substituído do mais potente antagonista) devido à presença da fenilalanina 249 (ou 617 na nomenclatura de Hibert et al.) e de outro campo indicando bloqueio estéreo no plano paralelo e abaixo do anel do ligante, possivelmente devido à presença do triptofano 246 (ou 613 na nomenclatura de Hibert et al.). Note que a presença destes dois resíduos protéicos nesta disposição não constitui impedimento para ligantes contendo anéis aromáticos ou heterocíclicos de 5 membros e, portanto, com uma grande superfície molecular como indicam as QSARs 3 e 10. A Figura 4 mostra a ambiência química global em torno do mais potente antagonista determinada pelos métodos aqui utilizados.

A distribuição do campo molecular eletrostático mostra-se contínua ao longo da superfície do ligante (Figura 5), e sugere que uma transferência de carga positiva entre esta região é factível, e pode ser favorecida pelo grupo $\mathrm{NH}$ do triptofano 613 (décima terceira posição na hélice 6). Portanto, a presença de nitrogênios substituídos ao longo da superfície do ligante aumentando a afinidade pelos sítios primário e secundário é compatível com a forma e distribuição deste campo, e mostra a coerência das QSARs 11 e 12. Importa observar também que as regiões em torno dos fragmentos $-\mathrm{NH}_{2}$ são particularmente favoráveis à interação com sítios doadores de prótons. Nas hélices 5 e 6 do receptor $\mathrm{H}_{2}$ estes sítios doadores são grupos fenólicos de tirosinas direcionados para o interior da cavidade lipofílica e, portanto, o modelo baseado na análise comparativa dos campos moleculares é corroborado pelas validações laterais das QSARs-3D. Interações com resíduos fenólicos das hélices 5 e 6 do receptor $\mathrm{H}_{2}$ foram propostas para a classe imidazolilpropilguanidinas ${ }^{12}$ com o receptor $\mathrm{H}_{2}$, baseadas em QSAR-3D, e mostram a coerência do modelo aqui proposto.

\section{CONCLUSÕES}

O modelo proposto para os sítios de interação dos antagonistas $\mathrm{H}_{2}$, na forma desprotonada e na conformação estendida, postula a interação dos grupos fenólicos das tirosinas das hélices 5 e 6 do receptor $\mathrm{H}_{2}$ com as subunidades estruturais dos antagonistas - o grupo equivalente à uréia e ao anel heterocíclico substituído. Estas proposições estão baseadas num modelo de adsorção, no qual dois sítios ativos estão envolvidos e cujas constantes de afinidades apresentam valores similares com aquelas obtidas através da isoterma de interação dos antagonistas na presença da histamina. A análise comparativa dos campos moleculares estéreos e eletrostáticos revelou, ainda, a possibilidade da interação do anel aromático de um resíduo de fenilalanina e de um triptofano com o anel heterocíclico do antagonista, como sugerido no modelo de Hibert para ligantes que interagem com os GPCRs. Estas proposições estão baseadas nas QSARS - 3D, na QSAR clássica e nas suas respectivas validações, bem como nas distribuições dos campos moleculares estéreos e eletrostáticos.

Importa acrescentar que o novo modelo proposto é compatível com os dados farmacológicos obtidos, pois um antagonista pode interagir com o receptor ligando-se às tirosinas das hélices 5 e 6 , e a histamina (o agonista) pode permanecer temporariamente ligada ao receptor pelo aspartato na hélice 3 . O bloqueio de tirosinas pelos antagonistas sugere que o receptor $\mathrm{H}_{2}$ possa ser ativado por um fluxo de prótons, como igualmente sugerido por Nederkoorn et al. ${ }^{4}$ no modelo da bomba de prótons envolvendo o agonista, baseado em modelagem molecular.

A possibilidade de o receptor histaminérgico $\mathrm{H}_{2}$ ser uma bomba de prótons secundária é instigadora, como sugerida pelas validações 
laterais das QSARs - 3D aqui apresentadas, e indica uma razão para não haver uma ramificação comum do receptor histaminérgico $\mathrm{H}_{2}$ com os receptores $\mathrm{H}_{1}$ e $\mathrm{H}_{3}$, como mostrado na filogênese molecular.

\section{AGRADECIMENTOS}

Os autores agradecem às agências financiadoras CNPq, CAPES e FAPEMIG que possibilitaram a elaboração deste trabalho.

\section{REFERÊNCIAS}

1. Gantz, I.; Munzet, G.; Tashiro, T.; Schäffer, M.; Wang, L.; DelValle, J.; Yamada, T.; Biochem. Biophys. Res. Commun. 1991, 178, 1386; Kelley, M. T.; Bürckstümmer, T.; Wenzel-Seifert, K.; Dove, S.; Buschauer, A.; Seifert, R.; Mol. Pharmacol. 2001, 60, 1210; Palczewski, K.; Kumasaka, T.; Hori, T.; Behnke, C. A.; Motoshima, H.; Fox, B. A.; Le Trong, I.; Teller, D. C.; Okada, T.; Stenkamp R. E.; Yamamoto, M.; Miyano, M.; Science 2000, 289, 739.

2. Oliveira, L.; Paiva, A. M. C.; Vriend, G.; J. Comput.-Aided Mol. Des. 1993, 7, 649; Kopin, A. S.; McBride, E. W.; Schaffer, K.; Beinborn, M.; Trends Pharmacol. Sci. 2000, 21, 346.

3. Vernier, P.; Cardinaud, B.; Philippe, H.; Vincent, J. D.; Ann. N. Y. Acad. Sci. 1997, 812, 141 .

4. Nederkoorn, P. H. J.; Tese de Doutorado, Vrije Universiteit, Holanda, 1996.

5. Kenakin, T.; Ann. N. Y. Acad. Sci. 1997, 812, 117.

6. Tian, W.-N.; Lanier, S. M.; Deth, R. C.; Mol. Pharmacol. 1994, 45, 524; Seifert, R.; Wenzel-Seifert, K.; Lee, W. T.; Gether, U.; Sanders-Bush, E.; Kobilka, B. K.; J. Biol. Chem. 1998, 273, 5109.

7. Nederkoorn, P. H. J.; van Gelder, E. M.; den Kelder, G. M. D. O.; Timmerman, H.; J. Comput.-Aided Mol. Des. 1996, 10, 479.

8. Giraldo, J.; Martín, M.; Campillo, M.; Pardo, L.; Mol. Pharmacol. 1992, 42, 373; Dove, S.; Buschauer, A.; Quant. Struct. - Act. Relat. 1999, 18, 329.

9. Breslow, R.; Acc. Chem. Res. 1991, 24, 317; Giraldo, J.; Biochem. Pharmacol. 1999, 58, 343.

10. Koji-Prodi, B.; Ru•i-Toroš., Z.; Bresciani-Pahor N.; Randaccio, L.; Acta Crysttalogr., Section B: Struct. Sci. 1980, 36, 1223; Cemik, R. J.; Prout, C. K.; Watkin, D. J.; Wilkinson, A. P.; Willis, B. T. M.; J. Appl. Crystallogr. 1991, 24, 222.

11. Ishida, T.; In, Y.; Shibata, M.; Doi, M.; Inque, M.; Yanagisawa, I.; Mol. Pharmacol. 1987, 31, 410; Hill, S. J.; Ganellin, C. R.; Timmerman, H.; Scharwtz, J. C.; Shankley, N. P.; Young, J. M.; Schunack, W.; Levi, R.; Haas, H. L.; Pharmacol. Rev. 1997, 49, 253.
12. Dove, S.; Buschauer, A.; Pharm. Acta Helv. 1998, 73, 145.

13. Krielaart, M. J.; Veenstra, D. M. J.; van Buuren, K. J. H.; Agents and Action 1990, 31, 23; Alewijnse, A. E.; Smit, M. J.; Hoffmann, M.; Verzijl, D.; Timmerman, H.; Leurs, R.; J. Neurochem. 1998, 71, 799.

14. Palm, C.; Luthman, K.; Ros, J.; Grajo, A. P.; J. Pharmacol. Exp. Ther. 1999, 291, 435.

15. Bastiaans, H. M. M.; Doneti, A.; Kramer, K.; Bietti, G.; Cereda, E.; Dubini, D.; Mondini, M.; Bast, A.; Timmerman, H.; Agents and Actions 1990, 30, 166

16. Stark, H.; Sippl, W.; Ligneau, X.; Arrang, J. M.; Ganellin, C. R.; Schwartz, J. C.; Schunack, W.; Bioorg. Med. Chem. 2001, 11, 951.

17. Montanari, M. L. C.; Montanari, C. A.; Gaudio, C. A.; Quim. Nova 2002, 25, 231.

18. Hansch, C.; Garg, R.; Kurup, A.; Bioorg. Med. Chem. 2001, 9, 283.

19. Gaudio, C. A.; Zandonade, E.; Quim. Nova 2001, 24, 658.

20. Shankley, N. P.; Black, J. W.; Ganellin, C. R.; Mitchell, R. C.; Br. J. Pharmacol. 1988, 94, 264.

21. Sybyl v.6.5.3. Tripos Inc.

22. TSAR, V.3.21. Oxford Molecular, Ltd., Oxford: U.K.

23. Bushelev, S.; Ann. N. Y. Acad. Sci. 1992, 661, 180; Burton, P. S.; Goodwin, J. T.; Vidmar, T. J.; Amore, B. M.; J. Pharmacol. Exp. Ther. 2002, 303, 889.

24. Gouldson, P. R.; Snell, C. R.; Reynolds, C. A.; J. Med. Chem. 1997, 40, 3871.

25. Hibert, M. F.; Kallmeyer, S.T.; Bruinsvels, A.; Hoflack, J.; Mol. Pharmacol. 1991, 40, 8; Hibert, M. F.; Kallmeyer, S. T.; Paquet, J.; Hoflack, L.; Leppik, R. Em QSAR and Molecular Modelling: Concepts, Computational Tools and Biological Applications; Sanz, F.; Giraldo, J.; Manaut, F., eds.; J. R. Prous Science Publishers: Barcelona, 1995, p. 508.

26. Abraham, M. H.; Duce, P. P.; Prior, D. V.; J. Chem. Soc. Perkin Trans. 2 1989, 1355

27. Timms, D.; Wilkinson, A. J.; Kelly, D. R.; Broadley, K. J.; Davies, R. H.; Int. J. Quant. Chem. 1992, 19, 197; Nederkoorn, P. H. J.; Timmerman, H.; Timms, D.; Wikinson, A. J.; Kelley, D. R.; Broadley, K. J.; Davies, R. H.; J. Mol. Struct. Theochem. 1998, 452, 25.

28. Broadley, K.; Nederkoorn, P. H. .J.; Timmerman, H.; Timms, D.; Davies, R. H.; J.Theor. Biol. 2000, 205, 297.

29. Klopman, G.; Kalos, A. N.; J. Theor. Biol. 1986, 118, 199; Isogaya, M.; Sugimoto, Y.; Tanimura, R.; Tanaka, R.; Kikaawa, H.; Nagao, T.; Kurose, H.; Mol. Pharmacol. 1999, 56, 875. 